\title{
Evaluation of test characteristics of 2 ELISA tests applied to bulk tank milk and claw-trimming records for herd-level diagnosis of bovine digital dermatitis using latent class analysis
}

\author{
Ingrid H. Holmøy, ${ }^{1 *} \odot$ Lina Ahlén, ${ }^{1}$ Jenny Frössling, ${ }^{2,3} \odot$ Liv Sølverød, ${ }^{4}$ Menno Holzhauer, ${ }^{5}$ Ane Nødtvedt, ${ }^{1} \odot$ \\ and Terje Fjeldaas ${ }^{1}$ (D) \\ ${ }^{1}$ Department of Production Animal Clinical Sciences, Faculty of Veterinary Medicine, Norwegian University of Life Sciences, PO Box 369 Sentrum, \\ $\mathrm{N}-0102$ Oslo, Norway \\ ${ }^{2}$ Department of Disease Control and Epidemiology, National Veterinary Institute (SVA), SE-751 89 Uppsala, Sweden \\ ${ }^{3}$ Department of Animal Environment and Health, Swedish University of Agricultural Sciences, PO Box 234, SE-532 23 Skara, Sweden \\ ${ }^{4}$ TINE SA, PO Box 2038, N-6402 Molde, Norway \\ ${ }^{5}$ GD Animal Health, PO Box 9, 7400 AA Deventer, the Netherlands
}

\begin{abstract}
Bovine digital dermatitis (DD) is an infectious claw disease with a negative effect on animal welfare and production. Treponema spp. is the main causative agent, and infected animals produce specific antibodies. Our aim was to estimate sensitivity (Se) and specificity ( $\mathrm{Sp}$ ) of 2 ELISA research tests, Medicago's ELISA test and GD Animal Health's in-house ELISA test, for detection of DD-associated Treponema antibodies in bulk tank milk. We used bulk tank milk samples from 154 Norwegian dairy cattle herds, 96 from an expected highprevalence region and 58 from a low-prevalence region. Both tests were evaluated separately against herd-level (aggregated) claw-trimming records extracted from the Norwegian Dairy Herd Recording System using latent class models in a Bayesian analysis. Cutoff values were selected using an explorative approach, and both noninformative priors for all parameters and informative $\beta$ priors for distribution of Se and Sp of claw trimming were explored. The estimated (median) true herdlevel prevalence of digital dermatitis varied between 24 and $30 \%$ in the high-prevalence region and between 3 and $6 \%$ in the low-prevalence region. For Medicago's ELISA test, an Se (95\% posterior credible interval) of $0.57(0.32 ; 0.94)$ could be achieved without compromising Sp, and for GD Animal Health's in-house ELISA test, an Se of $0.60(0.37 ; 0.92)$ was achieved. Our study showed that both ELISA tests can detect antibodies against DD-associated Treponema spp. in bulk tank milk. However, neither of the 2 ELISA tests produced satisfactory sensitivity without compromising specific-
\end{abstract}

Received October 19, 2020.

Accepted April 20, 2021.

*Corresponding author: ingrid.hunter.holmoy@nmbu.no ity. Based on these results, inspection at claw trimming in a chute is necessary for surveillance and control of DD at the herd level in Norway, although these ELISA tests of bulk tank milk might be a useful supplement. Key words: Bayesian analysis, dairy cattle, sensitivity, specificity, digital dermatitis

\section{INTRODUCTION}

Digital dermatitis (DD) is a widely distributed contagious bovine claw disease that first was described as a clinical condition in a dairy herd in Italy by Cheli and Mortellaro (1974). It is considered endemic in almost every country where dairy cattle are housed and is also frequently recorded in countries with grass-based production systems (Becker et al., 2014; Evans et al., 2016). The lesions can be very painful, and previous studies have shown that DD has a negative effect on animal welfare, milk and meat production, and fertility (Relun et al., 2013; Gomez et al., 2015). The first case of DD in Norway was reported in 2001, and even in 2010 few cases were recorded (Forshell et al., 2001; Knappe-Poindecker et al., 2013). More recent figures show that approximately $17 \%$ of Norwegian dairy herds are or have been DD positive in the period from introduction of the Nordic electronic recording of claw diseases in 2014 until May 2020. Compared with most other countries with a longer DD history, the lesions are smaller and milder in Norwegian dairy cattle (Ahlén and Fjeldaas, 2019).

The cause of the disease is multifactorial. Both environmental factors, such as poor hygiene in the cubicles and alleys, and genetic characteristics and host immunity are important for the etiology and pathogenesis of DD (Wells et al., 1999; Sogstad et al., 2005; Somers et al., 2005; Holzhauer et al., 2006). Even though studies have identified several bacteria in DD lesions, Trepone- 
ma spp. are the only infectious agents with substantial evidence of etiological association (Evans et al., 2008, 2016; Sullivan et al., 2015; Nielsen et al., 2016). Once established in a herd, DD usually shows a dynamic appearance with acute or chronic stages in different animals and is challenging to eradicate (Döpfer et al., 2012).

The traditional diagnostic method used to detect DD is visual assessment and recording of clinical signs, preferably by restraining of cows in a chute, cleaning of the feet, and inspection of the interdigital, coronary, and plantar skin (ICAR WGFT and International Claw Health Experts, 2020). All individuals should be restrained and examined before the herd is declared as being DD free. This is time consuming and expensive, and requires personnel specially trained in diagnosing claw diseases. Consequently, a laboratory test to diagnose DD on herd level would be desirable. Studies have shown that infections with Treponema spp. cause production of specific antibodies (Trott et al., 2003; Moe et al., 2010; Gomez et al., 2014).

The properties of a diagnostic test are defined by the test's sensitivity (Se) and specificity (Sp). New diagnostic tests are often evaluated against a reference test (the "gold standard"). A Swedish study showed that an ELISA antibody test based on the Treponema phagedenis antigens proline-rich repeat protein A (PrrA), VpsA, and VpsB in parallel testing could distinguish between DD-negative and DD-positive individuals (Frössling et al., 2018). They obtained relative Se of $60.7 \%$ and $\mathrm{Sp}$ of $87.9 \%$ using serum samples for analysis, and clinical status of individual cows as the reference test. Bulk tank milk (BTM) test performance showed an Se of $80 \%$ and Sp of $100 \%$ using clinical data aggregated from the individual level to the herd level as the reference test (Frössling et al., 2018). These results suggest that analysis of BTM for Treponema antibodies could be useful in the assessment of DD status in herds and that BTM testing could provide an option for surveillance of disease progress or be the basis of a control program.

Diagnostic tests should be evaluated in the population in which they are intended to be used (Greiner and Gardner, 2000). However, perfect reference tests are rarely available. In latent class analysis (LCA), the true disease status of a herd or an individual animal is considered a latent variable; that is, an existing but unknown entity. Estimates of Se, Sp, and true prevalence are parameterized according to this latent variable. Further, it is important to validate the test for the intended use as test accuracy varies across applications (e.g., herd-level test vs. individual animal test; Christensen and Gardner, 2000). It is therefore of interest to estimate test characteristics at different cutoffs for herd-level use.

Our aim was to estimate Se and Sp of 2 research tests for detection of DD-associated Treponema antibodies in BTM and thereby assess their usefulness for DD surveillance under Norwegian conditions. Both tests were compared with herd-level aggregated claw-trimming records from professional trimmers, using LCA.

\section{MATERIALS AND METHODS}

\section{Study Population and Sample Collection}

Herds that were members of the Norwegian Dairy Herd Recording System (NDHRS) were eligible for inclusion. The NDHRS is a nationwide recording system that contains information on cow pedigree, production, and health of individual animals in enrolled herds. The recording system is managed by TINE SA, the largest dairy company in Norway. In 2018, $94.6 \%$ of Norwegian dairy herds were enrolled (Østerås, 2020; Statistics Norway, 2020). The inclusion criteria were that herds had to have at least 1 claw-trimming event registered during the preceding year and consist of at least 15 cows. Eligible herds from 2 regions with an expected difference in true prevalence were selected to meet model requirements for LCA (described later). The Sogn og Fjordane region is in western Norway and was assumed to have a relatively low herd-level prevalence of DD based on information from claw trimmers and veterinarians. The Rogaland region is in southwestern Norway and was thought to have a higher herd-level prevalence. In Sogn og Fjordane, we chose to select all herds that met the inclusion criteria $(\mathrm{n}=100)$ for BTM sampling. From Rogaland, 150 (out of 260 eligible herds) were randomly chosen for BTM sampling using computer-generated random numbers. Bulk tank milk samples were collected from the selected farms in the period from September 20 to October 26, 2018. The samples were collected by the milk truck driver at ordinary milk collection times using standard protocols for BTM sampling. The BTM samples were stored at $4^{\circ} \mathrm{C}$ until received at the laboratory (TINE Mastitis Laboratory, Molde, Norway). On arrival, all samples were frozen until analysis with Medicago's ELISA test (April to June 2019). The remaining sample material was frozen again immediately after analysis and stored until transportation under frozen condition overnight to GD Animal Health's laboratory in Deventer, the Netherlands. All samples arrived in good condition on August 29, 2019, and were analyzed using GD Animal Health's in-house test shortly after arrival (in early September). 


\section{Diagnostic Tests}

Medicago's ELISA Test. Medicago's ELISA test, which is a prototype test for research purposes only, was used on all available BTM samples $(\mathrm{n}=219)$. The test contains 1 immunogenic protein, PrrA, for detection of antibodies against T. phagedenis. The protein was purified as described by Rosander et al. (2011). Before ELISA testing, BTM samples and control samples were diluted on a sample dilution plate. The BTM samples were diluted $1: 2$ by adding $120 \mu \mathrm{L}$ of tank milk sample to the bottom of the dilution plate wells, followed by $120 \mu \mathrm{L}$ of PBS containing $0.05 \%$ (wt/vol) Tween 20 (PBS-Tween). Positive and negative control samples were diluted according to manual, using $95 \mu \mathrm{L}$ of PBSTween and $5 \mu \mathrm{L}$ of control sample to each well of the sample dilution plate and mixed thoroughly.

Reagents and diluted samples were held at room temperature before use, as described in the procedure manual. For controls, $90 \mu \mathrm{L}$ of PBS-Tween was added to all wells of the coated ELISA plate, followed by 10 $\mu \mathrm{L}$ of diluted control samples from the sample dilution plate; $100 \mu \mathrm{L}$ of diluted BTM samples from the sample dilution plate was added to the coated ELISA plate. Plates were covered with sealing tape and incubated for $2 \mathrm{~h}$ at $37^{\circ} \mathrm{C}$. After the initial incubation, plates were emptied and washed 6 times with $350 \mu \mathrm{L}$ of PBSTween; then, $100 \mu \mathrm{L}$ of diluted horseradish peroxidase (HRP) conjugate was added to each well. Plates were sealed and incubated again for $1 \mathrm{~h}$ at $37^{\circ} \mathrm{C}$. The plates were emptied and washed 6 times with $350 \mu \mathrm{L}$ of PBSTween, and $100 \mu \mathrm{L}$ of EC-Blue Enhanced Substrate (tetramethylbenzidine) was added to each well. After $10 \mathrm{~min}$ at room temperature, the reaction was stopped by adding $50 \mu \mathrm{L}$ of stop solution.

Optical density at $450 \mathrm{~nm}\left(\mathrm{~A}_{450}\right)$ was measured using a microtiter reader within $15 \mathrm{~min}$ of finishing the assay. Negative and positive control samples were included on each plate. All BTM samples and controls were analyzed in duplicate, 2 samples side by side, under strictly controlled and recorded procedures. For each duplicate, the mean optical density was calculated. Percent positivity (PP) was calculated for each BTM sample relative to the positive control, $\mathrm{PP}=\left[100 \times \mathrm{A}_{450}\right.$ (test sample - blank $) /\left(\mathrm{A}_{450} \times(\right.$ positive control - blank $\left.)\right]$. Medicago's recommended cutoffs for BTM samples, based on the Swedish dairy herd population, were as follows: $\mathrm{PP} \geq 27=$ positive, $\mathrm{PP}<27=$ negative, 22 $<\mathrm{PP}<32=$ recheck. The laboratory personnel were blinded concerning herd DD status.

GD Animal Health's In-House ELISA Test. The BTM samples were tested for Treponema spp. antibodies using an indirect ELISA based on a mixture of whole-cell antigens. Treponema phagedenis, Trepo- nema vincentii, Treponema denticola, and Treponema pedis cells were cultured, harvested by centrifugation, washed in PBS twice, and disrupted by ultrasound treatment. The suspension was centrifuged at 5,000 $\times$ $g$ for $20 \mathrm{~min}$ at room temperature to remove insoluble particles, and the supernatant was aliquoted and stored at $-20^{\circ} \mathrm{C}$ until used. The ELISA plates (Greiner high binding) were coated with $100 \mu \mathrm{L}$ of whole-cell antigens diluted in coating buffer $(9.8 \mathrm{~g} / \mathrm{L}$ ammonium carbonate) and incubated overnight at $4^{\circ} \mathrm{C}$. The plates were blocked by adding $100 \mu \mathrm{L}$ of blocking buffer $(20 \mathrm{~g} / \mathrm{L}$ sucrose and $4 \mathrm{~g} / \mathrm{L}$ casein in coating buffer). After a 1-h incubation at room temperature, the wells were emptied by flicking. Subsequently, the plates were dried for $4 \mathrm{~h}$ at $37^{\circ} \mathrm{C}$, sealed under vacuum, and stored at 2 to $8^{\circ} \mathrm{C}$ until used. Bulk tank milk samples were tested undiluted by pipetting $100 \mu \mathrm{L}$ into the wells of a coated plate. The plates were incubated for $1 \mathrm{~h}$ at room temperature and then washed 5 times using $300 \mu \mathrm{L} /$ well washing liquid (PBS-Tween) using an automatic washer (Biotek). Subsequently, $100 \mu \mathrm{L}$ of conjugate (Abcam AB7460), diluted 1:25,000 in test buffer (PBS-Tween and $4 \mathrm{~g} / \mathrm{L}$ casein) was added, and the plates were incubated for $1 \mathrm{~h}$ at room temperature. After washing the test plate 5 times with $300 \mu \mathrm{L} /$ well washing liquid, $100 \mu \mathrm{L}$ of tetramethylbenzidine substrate solution (Idexx) was added. After a 30-min incubation at room temperature, the reaction was stopped by the addition of $50 \mu \mathrm{L}$ of 2 $M \mathrm{H}_{2} \mathrm{SO}_{4}$ to each well. Optical densities were measured using a plate reader (Mikrotek) at a wavelength of 450 $\mathrm{nm}$. Sample to positive ratios $(\mathbf{S} / \mathbf{P})$ were calculated for each sample relatively to the positive control sample included in each test plate. The recommended cutoffs for BTM from the Dutch dairy cattle population were as follows: S/P ratio $<0.867=$ low level of antibodies, $\mathrm{S} / \mathrm{P}$ ratio 0.867 to $1.242=$ high level of antibodies, and $\mathrm{S} / \mathrm{P}$ ratio $>1.242=$ very high level of antibodies. The laboratory personnel were blinded concerning the result of the corresponding Medicago ELISA test.

Claw Trimming. Average annual herd size for 2018 and individual animal claw-trimming records pertaining to the period from March 2018 to April 2019 were extracted from the NDHRS. Claw diagnoses are recorded according to the Nordic Claw Atlas (Nordic Ruminant Lameness Research Network, 2013).

Individual animal claw-trimming records were aggregated by herd and date, hereafter designated "clawtrimming events." The number of animals trimmed and the number of animals with recorded DD were counted per claw-trimming event. For descriptive purposes, remarks other than DD were also aggregated. Only events in which at least $70 \%$ of the cows in a herd were trimmed were considered. Claw-trimming events occurring more than 6 mo before or 1 mo after the 
Table 1. Overall within-herd prevalence and individual animal prevalence by region for the most frequently occurring claw disorders recorded at claw trimming

\begin{tabular}{lccc}
\hline & $\begin{array}{c}\text { Within-herd } \\
\text { prevalence } \\
\text { Clmedian (range) }\end{array}$ & $\begin{array}{c}\text { High-prevalence } \\
\text { region [n (\%)] }\end{array}$ & $\begin{array}{c}\text { Low-prevalence } \\
\text { region [n (\%)] }\end{array}$ \\
\cline { 3 - 4 } Corkscrew claw & $0.02(0-0.52)$ & $459(9.5)$ & $220(10.3)$ \\
V-shaped heel horn erosion & $0.04(0-0.44)$ & $460(9.5)$ & $124(5.8)$ \\
Sole hemorrhage & $0.05(0-0.41)$ & $202(4.2)$ & $328(15.4)$ \\
White line fissure or abscess & $0.08(0-0.57)$ & $296(6.7)$ & $142(6.1)$ \\
\hline
\end{tabular}

BTM sample from a herd were excluded from further analysis.

The included herd claw-trimming events consisted of 6,953 individual cow trimmings, 4,822 in the high-prevalence region and 2,131 in the low-prevalence region. Most cows were trimmed by certified claw trimmers $[5,284 / 6,953(76.0 \%)]$. In both regions, around twothirds of the cows had no remarks at trimming. The overall within-herd prevalence of the most frequent claw disorders was recorded at trimming, and the individual animal prevalences by region are shown in Table 1 .

\section{Latent Class Analysis}

The 2 diagnostic tests were evaluated separately against herd-level aggregated claw-trimming records from professional trimmers using latent class models in a Bayesian analysis (Branscum et al., 2005). Threetest models accounting for dependence between the 2 ELISA tests were also pursued but disregarded because of failure to converge. The target condition for both tests under evaluation was $\geq 1$ animal with previous or current DD lesions producing antibodies against DDassociated Treponema spp. while contributing to the BTM, thus returning a herd-level diagnosis for DD. The latent state could be considered as previous or current exposure to treponemes, leading to DD lesions and antibodies in BTM. The LCA requires test results from at least 2 subpopulations with a difference in true prevalence for estimation of test characteristics (Hui and Walter, 1980). The 2 regions, Sogn og Fjordane and Rogaland, hereafter denoted the high-prevalence region and low-prevalence region, respectively, were used as distinct subpopulations in the model, assuming different herd-level prevalences. When using LCA, the model assumptions are constant Se and Sp of the diagnostic tests across the subpopulations and conditional independence between tests given the target condition. Cutoff values were selected using an explorative approach. As a starting point, the recommended cutoff values from the test manufacturer or developer were applied. Several different cutoff values were explored for each test (Table 2). To enable sensitivity analysis of the effect of priors, the models were first fit using noninformative priors $[\beta(1,1)]$ for all parameters. A second set of models was then fit using informative priors following the $\beta$ distributions for the Se $\{79[95 \%$ posterior credibility interval (PCI): $68 ; 88]\}$ and Sp [80 (95\% PCI: 71; 89)] of claw trimming from Ferraro et al. (2020). Test characteristics for claw trimming in Ferraro et al. (2020) were estimated relative to the current clinical DD status as determined by a borescope, using LCA. The $\alpha$ and $\beta$ parameters of the $\beta$ distribution were calculated using the epi.betabuster function from the epiR package (Stevenson et al., 2017). The complete set of input values $(\mathrm{a}, \mathrm{b})$ for the prior distributions were $(58.357,16.251)$ for Se and $(48.283,12.820)$ for Sp. The simulations were run for 20,000 iterations of each model using 3 different sets of starting values, where the first 10,000 iterations were discarded as the burn-in phase. Convergence of models was evaluated by visual inspection of the time-series plots of the parameters, as well as by Gelman-Rubin diagnostic plots (Toft et al., 2007). Data preparation and descriptive analysis were performed in Stata (Stata SE version 15; Stata Corp.). OpenBUGS software (version 3.2.3, rev 1012) was used for LCA. The guidelines on reporting diagnostic accuracy for studies using Bayesian latent class models were consulted during preparation of this paper (Kostoulas et al., 2017).

\section{RESULTS}

\section{Descriptive Statistics}

ELISA test results were available for 219 BTM samples from 219 herds, 1 from each herd. Of these, 65 samples were excluded from further analysis due to lack of a relevant claw-trimming result; details are given in Figure 1. Thus, results from 154 pairs of BTM samples and claw-trimming results were included in the LCA, with 96 samples from the high-prevalence region and 58 from the low-prevalence region. Descriptive statistics showed that within the chosen timeframe, $34(22.1 \%)$ of 
Table 2. Number (\%) of positive bulk tank milk samples at different cutoff values for Medicago's ELISA test and GD Animal Health's inhouse ELISA test $(\mathrm{n}=154)$

\begin{tabular}{|c|c|}
\hline $\begin{array}{l}\text { Medicago ELISA } \\
\text { cutoff }\left(\mathrm{PP}^{1}\right)\end{array}$ & $\begin{array}{c}\mathrm{n}(\%) \\
\text { positive }\end{array}$ \\
\hline 27 & $4(2.6)$ \\
\hline 22 & $6(3.9)$ \\
\hline 15 & $11(7.1)$ \\
\hline 10 & $19(12.3)$ \\
\hline 7 & $43(27.9)$ \\
\hline 6 & $59(38.3)$ \\
\hline \multicolumn{2}{|c|}{ In-house ELISA cutoff $\left(\mathrm{S} / \mathrm{P}^{2}\right)$} \\
\hline 1.242 & $0(0)$ \\
\hline 0.867 & $1(0.06)$ \\
\hline 0.7 & $9(5.8)$ \\
\hline 0.6 & $22(14.3)$ \\
\hline 0.5 & $42(27)$ \\
\hline 0.45 & $58(37.7)$ \\
\hline
\end{tabular}

${ }^{1} \mathrm{PP}=$ percent positivity.

${ }^{2} \mathrm{~S} / \mathrm{P}=$ sample-to-positive ratio.

the herds had at least 1 cow diagnosed with DD as assessed by the claw trimmer. The corresponding values for the 2 regions were $31(32.3 \%)$ in the high-prevalence region and $3(5.2 \%)$ in the low-prevalence region. The median proportion of DD-affected individuals per clawtrimming event in affected herds was 0.062 (range: 0.01 to 0.32 ). The number (\%) of positive samples at different cutoff values of PP for the Medicago ELISA test and S/P ratios for the GD Animal Health's in-house ELISA test are presented in Table 2. Counts of paired test outcomes for the tests and claw-trimming records are shown in Table 3 and Table 4 for the Medicago ELISA and GD Animal Health's in-house ELISA tests, respectively.

\section{Latent Class Analyses}

None of the 3-test models applied attained convergence. Therefore, 2-test models were applied, evaluating each of the 2 diagnostic tests separately against herd-level aggregated claw-trimming records.

Medicago's ELISA Test. The recommended cutoff values from the test manufacturer were applied as a starting point (PP 27 and PP 22). The highest cutoff value (PP 27) resulted in a median (95\% PCI) Se of $0.16(0.04 ; 0.49)$ and Sp of $0.99(0.96 ; 1.00)$ for Medicago's ELISA test, and Se $0.79(0.69 ; 0.87)$ and Sp 0.87 $(0.79 ; 0.92)$ for claw trimming. Decreasing the cutoff value for the PrrA antigen resulted in higher Se and lower Sp estimates for the ELISA test, as would be expected. An Se of $0.57(0.32 ; 0.94)$ could be achieved without compromising on the Sp (cutoff PP 10). The highest Se was achieved using lowest cutoff value $[\mathrm{PP}$ 5 : Se $0.82(0.59 ; 0.98)]$ but at the expense of an unacceptably low Sp $[0.51(0.41 ; 0.61)]$. The estimated true herd-level prevalence of DD (median point estimates) across the cutoffs tested ranged from 24 to $30 \%$ in the high-prevalence region and from 3 to $6 \%$ in the lowprevalence region. Estimates of median Se, Sp, and true prevalence in the 2 subpopulations for Medicago's ELISA and claw trimming when applying different cutoff values are presented in Table 5 . In the models using noninformative priors, convergence was not obtained for the cutoff-values 27 and 5 (Supplemental Table S1; https://doi.org/10.18710/R3ZTBN). In general, models using noninformative priors estimated lower Se for the ELISA test, and higher Se and Sp for claw trimming (across all cutoff values) compared with the models using informative priors.

GD Animal Health's In-House ELISA Test. Applying a cutoff of S/P 1.242 resulted in a median (95\% PCI) Se of $0.02(0.02 ; 0.14)$ and Sp of $0.99(0.97$; 1.00) for the in-house ELISA test, and Se 0.78 (0.68; $0.86)$ and Sp $0.87(0.79 ; 0.92)$ for claw trimming. As with the Medicago test, decreasing the cutoff value for the mixture of whole-cell antigens resulted in higher Se and lower Sp estimates for the ELISA test. An Se of $0.60(0.37 ; 0.92)$ could be achieved without compromising on Sp (cutoff S/P: 0.6). The highest Se was achieved at cutoff 0.45 , returning an Se of 0.86 (0.64; $0.99)$ and an $\mathrm{Sp}$ of $0.77(0.65 ; 0.85)$. The median point estimates of true herd-level DD prevalence ranged from 27 to $36 \%$ in the high-prevalence region and from 2 to $4 \%$ in the low-prevalence region across the cutoffs applied. Estimates of median Se, Sp, and true prevalence in the 2 subpopulations for GD Animal Health's in-house ELISA test when applying different cutoff values are presented in Table 6 . In the models using noninformative priors, convergence was not obtained for the 2 highest cutoff values. Furthermore, Se and Sp estimates of claw trimming and true prevalence in the 2 populations changed substantially across the applied cutoff values of the ELISA test, indicative of a violation of latent condition definition (Supplemental Table S2; https://doi.org/10.18710/R3ZTBN).

\section{DISCUSSION}

We estimated the sensitivity and specificity of 2 different ELISA tests for the detection of antibodies against DD-associated Treponema spp. in BTM samples from Norwegian dairy herds. The 2 diagnostic tests were evaluated separately against records from claw-trimming events using latent class models in a Bayesian analysis. Hence, Se and $\mathrm{Sp}$ estimates were also obtained for claw trimming. Our study confirms the results from a previous study: cows with DD lesions develop antibodies against T. phagedenis that can be measured in BTM using specific ELISA tests (Frössling 
et al., 2018). Estimated median Se (95\% PCI) ranged from $0.16(0.04 ; 0.49)$ to $0.82(0.59 ; 0.98)$ for Medicago's ELISA test and from $0.02(0.02 ; 0.14)$ to 0.86 $(0.64 ; 0.99)$ for GD Animal Health's in-house ELISA test, depending on the chosen cutoffs. However, the highest Se estimates were not achieved without substantially compromising Sp. Sensitivity parameters of both ELISA tests under evaluation in this study were substantially lower than those of the ELISA test evaluated by Frössling et al. (2018). Similar to our study, clinical data were aggregated from the individual level but, in contrast to the current analyses, the aggregated clinical data were considered a perfect reference test. Moreover, the ELISA test used by Frössling et al. (2018) contained 4 antigens from T. phagedenis (Ttm, VpsA, VpsB, and PrrA), whereas Medicago's ELISA test that we used only contained the PrrA antigen. Even though T. phagedenis is the most prevalent phylotype in DD lesions in Norway, a most recent fluorescence in situ hybridization (FISH) analysis showed that 22

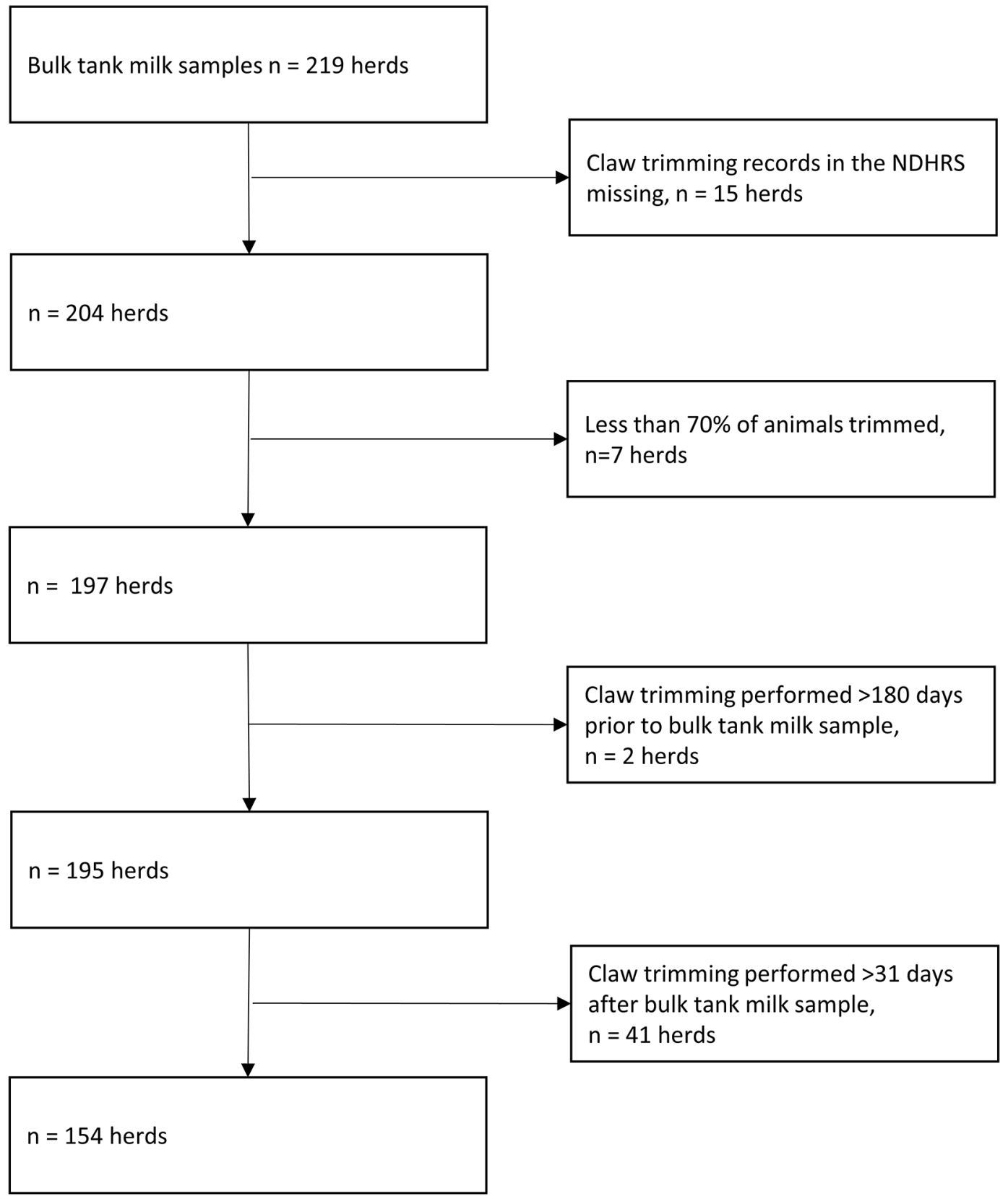

Figure 1. Flowchart of eligible samples, reasons for exclusions, and samples used for latent class analysis. NDHRS = Norwegian Dairy Herd Recording System. 
Table 3. Counts of paired test outcomes in the 2 subpopulations for the antibody test against digital dermatitis-associated Treponema phagedenis (PrrA; Medicago's ELISA test) and claw-trimming records using different cutoffs for the $\mathrm{PP}^{1}$ values

\begin{tabular}{|c|c|c|c|c|c|c|c|c|}
\hline \multirow{3}{*}{$\begin{array}{l}\text { Cutoff } \\
(\mathrm{PP})\end{array}$} & \multicolumn{8}{|c|}{ Medicago ELISA/claw trimming } \\
\hline & \multicolumn{4}{|c|}{$\begin{array}{l}\text { High-prevalence region } \\
\qquad(\mathrm{n}=96)\end{array}$} & \multicolumn{4}{|c|}{$\begin{array}{l}\text { Low-prevalence region } \\
\qquad(\mathrm{n}=58)\end{array}$} \\
\hline & $+/+$ & $+/-$ & $-/+$ & $-1-$ & $+/+$ & $+/-$ & $-/+$ & $-/-$ \\
\hline 27 & 3 & 0 & 28 & 65 & 1 & 0 & 2 & 55 \\
\hline 22 & 5 & 0 & 26 & 65 & 1 & 0 & 2 & 55 \\
\hline 15 & 8 & 0 & 23 & 65 & 2 & 1 & 1 & 54 \\
\hline 10 & 12 & 2 & 19 & 63 & 2 & 3 & 1 & 52 \\
\hline 7 & 19 & 8 & 12 & 57 & 2 & 14 & 1 & 41 \\
\hline 5 & 23 & 34 & 8 & 31 & 2 & 27 & 1 & 28 \\
\hline
\end{tabular}

${ }^{1} \mathrm{PP}=$ percent positivity.

of 105 cows with clinical DD lesions from 21 selected DD herds were negative for T. phagedenis (Tim Kåre Jensen, DTU - Technical University of Denmark, Copenhagen, personal communication).

Antibody tests based on whole-cell preparations of Treponema phagedenis from DD lesions have been evaluated for serology from individual animals (Gomez et al., 2014). Immunoenzymatic tests based on mixtures of whole-cell antigens have high Se and often serve as excellent screening tests, but their Sp might typically be low (Frank, 2002; Kodym et al., 2018). The GD Animal Health's ELISA test contains antigens based on a mixture of whole cells from the Treponema species phagedenis, vincentii, denticola, and pedis. Eight different phylotypes (PT) have so far been identified in Norway: PT 1, 2, 3, 6 (T. phagedenis), 11 (T. pedis), 13, 15, and 19 (Knappe-Poindecker et al., 2013; Tim Kåre Jensen, personal communication). Hence, only 2 of the $4 \mathrm{PT}$ in the GD Animal Health's ELISA test have been detected in Norway. Cross-reactivity between PT has been demonstrated (Elliott et al., 2007; Vink et al., 2009) We cannot exclude the possibility that $T$.
Table 4. Counts of paired test outcomes in the 2 subpopulations for the whole-cell antibody test against digital dermatitis-associated Treponema spp. (GD Animal Health's in-house ELISA) and clawtrimming records using different cutoffs for the $\mathrm{S} / \mathrm{P}$ ratios ${ }^{1}$

\begin{tabular}{|c|c|c|c|c|c|c|c|c|}
\hline \multirow{3}{*}{$\begin{array}{l}\text { Cutoff } \\
(\mathrm{S} / \mathrm{P})\end{array}$} & \multicolumn{8}{|c|}{ GD Animal Health ELISA/claw trimming } \\
\hline & \multicolumn{4}{|c|}{$\begin{array}{l}\text { High-prevalence region } \\
\qquad(\mathrm{n}=96)\end{array}$} & \multicolumn{4}{|c|}{$\begin{array}{l}\text { Low-prevalence region } \\
\qquad(\mathrm{n}=58)\end{array}$} \\
\hline & $+/+$ & $+/-$ & $-/+$ & $-/-$ & $+/+$ & $+/-$ & $-/+$ & $-/-$ \\
\hline 1.242 & 0 & 0 & 31 & 65 & 0 & 0 & 3 & 55 \\
\hline 0.867 & 1 & 0 & 30 & 65 & 0 & 0 & 3 & 55 \\
\hline 0.7 & 8 & 1 & 23 & 64 & 0 & 0 & 3 & 55 \\
\hline 0.6 & 13 & 8 & 18 & 57 & 1 & 0 & 2 & 55 \\
\hline 0.5 & 20 & 16 & 11 & 49 & 2 & 4 & 1 & 51 \\
\hline 0.45 & 22 & 25 & 9 & 40 & 2 & 9 & 1 & 46 \\
\hline
\end{tabular}

${ }^{1} \mathrm{~S} / \mathrm{P}=$ sample-to-positive ratio.

denticola and T. vincentii are present, but the limited number of PT matching the test may explain the low Se achieved. For both tests under evaluation, the estimates provided are examples of expected performance for different cutoffs and are not intended as an optimization of the diagnostic tests.

Test performance of herd-level tests for DD is rarely documented in the literature. However, evaluation of individual animal tests is more frequently carried out; for example, observation of presence or absence of DD lesions in the milking parlor. Using assessment in the trimming chute as a gold standard, various studies found relative Se estimates between 0.58 and 0.92 and relative Sp estimates between 0.80 and 0.95 (Thomsen et al., 2008; Relun et al., 2011; Solano et al., 2017; Cramer et al., 2018).

For both ELISA tests evaluated in this study, decreasing cutoffs to obtain a higher Se did not compromise Sp to a great extent, except when applying the lowest cutoffs. Note that the units of measurement are different for the 2 tests, hence cutoff values cannot be compared directly. The precision of the Se estimates

Table 5. Median test parameter estimates ${ }^{1}$ [95\% posterior credibility intervals (PCI)] for Medicago's ELISA test and claw-trimming records estimated using latent class analysis including informed priors for claw trimming from Ferraro et al. (2020)

\begin{tabular}{|c|c|c|c|c|c|c|c|c|c|c|c|c|}
\hline \multirow{2}{*}{$\begin{array}{l}\text { Cutoff } \\
\text { (PP) }\end{array}$} & \multicolumn{4}{|c|}{ Medicago's ELISA } & \multicolumn{4}{|c|}{ Claw trimming } & \multicolumn{4}{|c|}{ True prevalence } \\
\hline & Median & {$[95 \%$ PCI $]$} & Median & {$[95 \%$ PCI $]$} & Median & {$[95 \% \mathrm{PCI}]$} & Median & {$[95 \%$ PCI $]$} & Median & {$[95 \% \mathrm{PCI}]$} & Median & {$[95 \% \mathrm{PCI}]$} \\
\hline 27 & 0.16 & {$[0.04 ; 0.49]$} & 0.99 & {$[0.96 ; 1.00]$} & 0.79 & {$[0.69 ; 0.87]$} & 0.87 & {$[0.79 ; 0.92]$} & 0.27 & {$[0.08 ; 0.44]$} & 0.04 & {$[0.00 ; 0.13]$} \\
\hline 22 & 0.24 & {$[0.09 ; 0.60]$} & 0.99 & {$[0.96 ; 1.00]$} & 0.80 & {$[0.70 ; 0.87]$} & 0.87 & {$[0.80 ; 0.93]$} & 0.26 & {$[0.09 ; 0.42]$} & 0.04 & {$[0.00 ; 0.12]$} \\
\hline 7 & 0.76 & {$[0.50 ; 0.98]$} & 0.82 & {$[0.74 ; 0.89]$} & 0.80 & {$[0.70 ; 0.88]$} & 0.87 & {$[0.81 ; 0.93]$} & 0.27 & {$[0.15 ; 0.41]$} & 0.04 & {$[0.00 ; 0.15]$} \\
\hline 5 & 0.82 & {$[0.59 ; 0.98]$} & 0.51 & {$[0.41 ; 0.61]$} & 0.78 & {$[0.67 ; 0.86]$} & 0.87 & {$[0.81 ; 0.92]$} & 0.30 & {$[0.15 ; 0.47]$} & 0.03 & {$[0.00 ; 0.12]$} \\
\hline
\end{tabular}

${ }^{1}$ Sensitivity (Se), specificity (Sp), and estimates of true prevalence in the 2 subpopulations at different percent positivity (PP) cutoff alternatives. 
Table 6. Median test parameter estimates ${ }^{1}$ [95\% posterior credibility intervals (PCI)] for GD Animal Health's in-house ELISA test and clawtrimming records estimated using latent class analysis including informed priors for claw trimming from Ferraro et al. (2020)

\begin{tabular}{|c|c|c|c|c|c|c|c|c|c|c|c|c|}
\hline \multirow{3}{*}{$\begin{array}{l}\text { Cutoff } \\
\left(\mathrm{S} / \mathrm{P}^{2}\right)\end{array}$} & \multicolumn{4}{|c|}{ In-house ELISA } & \multicolumn{4}{|c|}{ Claw trimming } & \multicolumn{4}{|c|}{ True prevalence } \\
\hline & \multicolumn{2}{|r|}{ Se } & \multicolumn{2}{|r|}{$\mathrm{Sp}$} & \multicolumn{2}{|r|}{ Se } & \multicolumn{2}{|r|}{ Sp } & \multicolumn{2}{|c|}{$\begin{array}{l}\text { High-prevalence } \\
\text { region }\end{array}$} & \multicolumn{2}{|c|}{$\begin{array}{l}\text { Low-prevalence } \\
\text { region }\end{array}$} \\
\hline & Median & {$[95 \% \mathrm{PCI}]$} & Median & {$[95 \%$ PCI $]$} & Median & {$[95 \% \mathrm{PCI}]$} & Median & {$[95 \% \mathrm{PCI}]$} & Median & {$[95 \% \mathrm{PCI}]$} & Median & {$[95 \%$ PCI $]$} \\
\hline 1.242 & 0.02 & {$[0.02 ; 0.14]$} & 0.99 & {$[0.97 ; 1.00]$} & 0.78 & {$[0.68 ; 0.86]$} & 0.87 & {$[0.79 ; 0.92]$} & 0.29 & {$[0.11 ; 0.46]$} & 0.02 & {$[0.00 ; 0.11]$} \\
\hline 0.867 & 0.06 & {$[0.01 ; 0.23]$} & 0.99 & {$[0.97 ; 1.00]$} & 0.78 & {$[0.68 ; 0.87]$} & 0.87 & {$[0.79 ; 0.92]$} & 0.28 & {$[0.10 ; 0.45]$} & 0.02 & {$[0.00 ; 0.11]$} \\
\hline 0.5 & 0.82 & {$[0.60 ; 0.99]$} & 0.89 & {$[0.80 ; 0.97]$} & 0.76 & {$[0.66 ; 0.85]$} & 0.88 & {$[0.82 ; 0.93]$} & 0.35 & {$[0.21 ; 0.51]$} & 0.04 & {$[0.00 ; 0.14]$} \\
\hline 0.45 & 0.86 & {$[0.64 ; 0.99]$} & 0.77 & {$[0.67 ; 0.86]$} & 0.77 & {$[0.65 ; 0.85]$} & 0.88 & {$[0.82 ; 0.93]$} & 0.36 & {$[0.21 ; 0.53]$} & 0.03 & {$[0.00 ; 0.12]$} \\
\hline
\end{tabular}

${ }^{1}$ Sensitivity (Se), specificity (Sp), and estimates of true prevalence in the 2 subpopulations at different cutoff alternatives.

${ }^{2} \mathrm{~S} / \mathrm{P}=$ sample-to-positive ratio.

and claw-trimming records were affected by the relatively few cases of DD, compared with the high number of negative cases, resulting in wide $95 \%$ PCI. The 2 test models required a total of 6 parameters to be estimated, Se and $\mathrm{Sp}$ for each test and true prevalence in the 2 populations. The total degrees of freedom (df) available were 6 [i.e., $K\left(2^{p}-1\right)$ where $p=$ tests and $K=$ populations] such that sufficient df were available to ensure model identifiability. For the pursued 3-test model, $14 \mathrm{df}$ were available with 9 parameters to be estimated. Thus, a low number of ELISA test-positive herds was the most likely reason for the observed convergence issues of the pursued 3-test models and some of the 2-test models using noninformative priors. Use of prior information provides extra information on which the estimation could be based, but potentially at the cost of very different median estimates.

The use of ELISA tests for analysis of BTM samples to detect herds with DD did not increase Se considerably compared with claw-trimming recordings, except for low cutoff values when the resulting ELISA Sp also was very low. A low Se test might still be beneficial for surveillance purposes given that $\mathrm{Sp}$ is sufficiently high, sample material is easy to obtain, and the test is relatively cheap. In general, the Sp of both ELISA tests were better than those of claw-trimming registrations when informative priors were included in the analysis. An advantage of using claw trimming for surveillance is that an electronic system for registration of claw diseases is already in place, and claw trimming in chutes is routinely carried out on most Norwegian farms.

To meet the requirement of the LCA model of (at least) 2 subpopulations with different prevalence, each region was included as a distinct population, assuming different true prevalences. Because violation of model assumptions might produce biased results, a careful evaluation is essential. We could not verify the assumption that the Se and Sp of the diagnostic tests should be constant across the subpopulations in this study. However, the Norwegian dairy population is relatively homogeneous in terms of breeds and production systems. Nevertheless, antigenic diversity between regions could be a potential source of variation in test characteristics across the 2 subpopulations. Studies have shown that different countries and even different regions in the same country can vary in terms of numbers and species of Treponema (Rasmussen et al., 2012). However, given the relatively recent introduction (Forshell et al., 2001; Knappe-Poindecker et al., 2013), antigen diversity may still be limited in Norway compared with countries where the disease has been endemic for decades.

The final assumption, conditional independence given the target condition, was fulfilled using tests with different modes for detection of DD (antibody detection and clinical registrations). A source of misclassification bias could be the time lag between claw-trimming events and BTM sampling. Claw-trimming events occurring from 6 mo before until 1 mo after BTM sampling were included as diagnostic events. This pragmatic approach was chosen to define a "clinically reasonable" window in time for included samples. Few studies have documented how long individual cows have persisting antibodies against Treponema spp. after the DD lesion is healed. Gomez et al. (2014) showed an elevated titer of antibodies in treated cows until $223 \mathrm{~d}$ after diagnosis.

The mean proportion of affected individuals per affected herd (as assessed by claw trimming) was low (6.9\%). Furthermore, small focal active or chronic lesions (M1 and M4.1) were most common in this population (Ahlén and Fjeldaas, 2019). A previous study reported on antibody response to different M-stages of DD lesion (Gomez et al., 2014). They found an increase in individual antibody production in the presence of large ulcerative lesions (M2) but no increase for small focal active or chronic lesions (M1 and M4.1; Gomez et al., 2014). Thus, the low Se obtained by both ELISA 
tests may result in part from a high proportion of lesions eliciting a low or absent immune response. Additionally, we cannot exclude the possibility that other Treponema PT not included in these 2 ELISA tests and even other non-Treponema species may have caused some of the DD lesions (Knappe-Poindecker et al., 2013; Evans et al., 2016). Finally, the low within-herd prevalence may cause antibodies to be diluted in the bulk milk and hence result in a lower Se.

\section{CONCLUSIONS}

This study shows that ELISA tests can detect antibodies against DD-associated Treponema spp. in bulk tank milk from Norwegian dairy herds. However, under Norwegian conditions with mild lesions and low within-herd prevalence of DD, neither Medicago's nor GD Animal Health's ELISA test produced acceptable sensitivity for detection of DD. Currently, inspection at claw trimming in a chute is necessary for surveillance and control of DD at the herd level in Norway, although these ELISA tests of bulk tank milk might be a useful supplement.

\section{ACKNOWLEDGMENTS}

The authors gratefully acknowledge Olav Østerås (TINE SA, Ås, Norway) for extraction and preparation of data from the Norwegian Dairy Herd Recording System (NDHRS). Access to these data was provided by NDHRS and TINE SA in agreement number 8/2017. This study was funded by The Norwegian Research Fund for Agriculture and Food Industry, Tine SA, and Animalia AS (Project No 267444). The authors have not stated any conflicts of interest.

\section{REFERENCES}

Ahlén, L., and T. Fjeldaas. 2019. Digital dermatitis and lameness-An evaluation of locomotion scoring as a tool to detect and control the disease. Pages 200-201 in Proc. 20th Int. Symp./12th Int. Conf. Lameness in Ruminants, Tokyo, Japan.

Becker, J., A. Steiner, S. Kohler, A. Koller-Bahler, M. Wuthrich, and M. Reist. 2014. Lameness and foot lesions in Swiss dairy cows: I. Prevalence. Schweiz. Arch. Tierheilkd. 156:71-78. https://doi.org/ 10.1024/0036-7281/a000553.

Branscum, A. J., I. A. Gardner, and W. O. Johnson. 2005. Estimation of diagnostic-test sensitivity and specificity through Bayesian modeling. Prev. Vet. Med. 68:145-163. https://doi.org/10.1016/j .prevetmed.2004.12.005.

Cheli, R., and C. M. Mortellaro. 1974. Digital dermatitis in cattle. Pages 208-213 in Proc. 8th International Meeting on Diseases of Cattle, Milan, Italy.

Christensen, J., and I. A. Gardner. 2000. Herd-level interpretation of test results for epidemiologic studies of animal diseases. Prev. Vet. Med. 45:83-106. https://doi.org/10.1016/S0167-5877(00)00118-5.

Cramer, G., T. Winders, L. Solano, and D. H. Kleinschmit. 2018. Evaluation of agreement among digital dermatitis scoring methods in the milking parlor, pen, and hoof trimming chute. J. Dairy Sci 101:2406-2414. https://doi.org/10.3168/jds.2017-13755.

Döpfer, D., M. Holzhauer, and M. Boven. 2012. The dynamics of digital dermatitis in populations of dairy cattle: Model-based estimates of transition rates and implications for control. Vet. J. 193:648-653. https://doi.org/10.1016/j.tvjl.2012.06.047.

Elliott, M. K., D. P. Alt, and R. L. Zuerner. 2007. Lesion formation and antibody response induced by papillomatous digital dermatitis-associated spirochetes in a murine abscess model. Infect. Immun. 75:4400-4408. https://doi.org/10.1128/IAI.00019-07.

Evans, N. J., J. M. Brown, I. Demirkan, R. D. Murray, W. D. Vink, R. W. Blowey, C. A. Hart, and S. D. Carter. 2008. Three unique groups of spirochetes isolated from digital dermatitis lesions in UK cattle. Vet. Microbiol. 130:141-150. https://doi.org/10.1016/ j.vetmic.2007.12.019.

Evans, N. J., R. D. Murray, and S. D. Carter. 2016. Bovine digital dermatitis: Current concepts from laboratory to farm. Vet. J. 211:3-13. https://doi.org/10.1016/j.tvjl.2015.10.028.

Ferraro, S., S. Buczinski, S. Dufour, M. Rousseau, J. Dubuc, J. P. Roy, and A. Desrochers. 2020. Bayesian assessment of diagnostic accuracy of a commercial borescope and of trimming chute exams for diagnosing digital dermatitis in dairy cows. J. Dairy Sci. 103:3381-3391. https://doi.org/10.3168/jds.2019-17129.

Forshell, K. P., T. Fjeldaas, K. M. Hjørungdal, and A. M. Kleppe. 2001. Klauvproblemer i en norsk storfebesetning - en kasusbeskrivelse. Nor. Vet.-Tidsskr. 113:775-778.

Frank, S. A. 2002. Chapter 4, Specificity and Cross-Reactivity. In Immunology and Evolution of Infectious Disease. Princeton University Press. https://www.ncbi.nlm.nih.gov/books/NBK2396/.

Frössling, J., A. Rosander, C. Björkman, K. Näslund, and M. Pringle. 2018. Detection of Treponema phagedenis-like antibodies in serum and bulk milk from cows with and without digital dermatitis. J. Vet. Diagn. Invest. 30:86-92. https://doi.org/10.1177/ 1040638717733778.

Gomez, A., K. S. Anklam, N. B. Cook, J. Rieman, K. A. Dunbar, K. E. Cooley, M. T. Socha, and D. Döpfer. 2014. Immune response against Treponema spp. and ELISA detection of digital dermatitis. J. Dairy Sci. 97:4864-4875. https://doi.org/10.3168/jds.2013 -7616 .

Gomez, A., N. B. Cook, M. Socha, and D. Döpfer. 2015. First-lactation performance in cows affected by digital dermatitis during the rearing period. J. Dairy Sci. 98:4487-4498. https://doi.org/10.3168/ jds.2014-9041.

Greiner, M., and I. A. Gardner. 2000. Application of diagnostic tests in veterinary epidemiologic studies. Prev. Vet. Med. 45:43-59. https: //doi.org/10.1016/S0167-5877(00)00116-1.

Holzhauer, M., C. Hardenberg, C. J. M. Bartels, and K. Frankena. 2006. Herd- and cow-level prevalence of digital dermatitis in the Netherlands and associated risk factors. J. Dairy Sci. 89:580-588. https://doi.org/10.3168/jds.S0022-0302(06)72121-X.

Hui, S. L., and S. D. Walter. 1980. Estimating the error rates of diagnostic tests. Biometrics 36:167-171. https://doi.org/10.2307/ 2530508

ICAR (International Committee for Animal Recording). 2020. ICAR Claw Health Atlas. 2nd ed. Accessed Aug. 5, 2020. https://www .icar.org/index.php/publications-technical-materials/technical -series-and-proceedings/atlas-claw-health-and-translations/.

Knappe-Poindecker, M., M. Gilhuus, T. K. Jensen, K. Klitgaard, R. B. Larssen, and T. Fjeldaas. 2013. Interdigital dermatitis, heel horn erosion, and digital dermatitis in 14 Norwegian dairy herds. J. Dairy Sci. 96:7617-7629. https://doi.org/10.3168/jds.2013-6717.

Kodym, P., Z. Kurzová, D. Berenová, D. Pícha, D. Smíšková, L. Moravcová, and M. Malý. 2018. Serological diagnostics of Lyme borreliosis: Comparison of universal and Borrelia species-specific tests based on whole-cell and recombinant antigens. J. Clin. Microbiol. 56:e00601-e00618. https://doi.org/10.1128/JCM.00601-18.

Kostoulas, P., S. S. Nielsen, A. J. Branscum, W. O. Johnson, N. Dendukuri, N. K. Dhand, N. Toft, and I. A. Gardner. 2017. STARDBLCM: Standards for the reporting of diagnostic accuracy studies that use Bayesian latent class models. Prev. Vet. Med. 138:37-47. https://doi.org/10.1016/j.prevetmed.2017.01.006. 
Moe, K. K., T. Yano, K. Misumi, C. Kubota, W. Yamazaki, M. Muguruma, and N. Misawa. 2010. Analysis of the IgG immune response to Treponema phagedenis-like spirochetes in individual dairy cattle with papillomatous digital dermatitis. Clin. Vaccine Immunol. 17:376-383. https://doi.org/10.1128/CVI.00464-09.

Nielsen, M. W., M. L. Strube, A. Isbrand, W. D. H. M. Al-Medrasi, M. Boye, T. K. Jensen, and K. Klitgaard. 2016. Potential bacterial core species associated with digital dermatitis in cattle herds identified by molecular profiling of interdigital skin samples. Vet. Microbiol. 186:139-149. https://doi.org/10.1016/j.vetmic.2016.03 .003 .

Nordic Ruminant Lameness Research Network. 2013. Nordic Claw Atlas. 2nd ed. Accessed Aug. 5, 2020. https://www.animalia.no/ contentassets/52118a17843e4e48a1bd5462061897cf/no-claw-atlas -2013-08-29-webb.pdf.

Østerås, O. 2020. Årsrapport helsekortordningen 2019, TINE SA. Accessed May 13, 2020. https://medlem.tine.no/fagprat/ husdyrkontrollen/\%C3\%A5rsrapport-helsekortordningen-2019.

Rasmussen, M., N. Capion, K. Klitgaard, T. Rogdo, T. Fjeldaas, M. Boye, and T. Jensen. 2012. Bovine digital dermatitis: Possible pathogenic consortium consisting of Dichelobacter nodosus and multiple Treponema species. Vet. Microbiol. 160:151-161. https:// doi.org/10.1016/j.vetmic.2012.05.018.

Relun, A., R. Guatteo, P. Roussel, and N. Bareille. 2011. A simple method to score digital dermatitis in dairy cows in the milking parlor. J. Dairy Sci. 94:5424-5434. https://doi.org/10.3168/jds 2010-4054.

Relun, A., A. Lehebel, M. Bruggink, N. Bareille, and R. Guatteo. 2013. Estimation of the relative impact of treatment and herd management practices on prevention of digital dermatitis in French dairy herds. Prev. Vet. Med. 110:558-562. https://doi.org/10.1016/j .prevetmed.2012.12.015.

Rosander, A., B. Guss, L. Frykberg, C. Björkman, K. Näslund, and M. Pringle. 2011. Identification of immunogenic proteins in Treponema phagedenis-like strain V1 from digital dermatitis lesions by phage display. Vet. Microbiol. 153:315-322. https://doi.org/10 .1016/j.vetmic.2011.06.005.

Sogstad, A. M., T. Fjeldaas, O. Østerås, and K. Forshell. 2005. Prevalence of claw lesions in Norwegian dairy cattle housed in tie stalls and free stalls. Prev. Vet. Med. 70:191-209. https://doi.org/10 .1016/j.prevetmed.2005.03.005.

Solano, L., H. W. Barkema, C. Jacobs, and K. Orsel. 2017. Validation of the M-stage scoring system for digital dermatitis on dairy cows in the milking parlor. J. Dairy Sci. 100:1592-1603. https:// doi.org/10.3168/jds.2016-11365.

Somers, J. G. C. J., K. Frankena, E. N. Noordhuizen-Stassen, and J. H. M. Metz. 2005. Risk factors for digital dermatitis in dairy cows kept in cubicle houses in the Netherlands. Prev. Vet. Med. 71:11-21. https://doi.org/10.1016/j.prevetmed.2005.05.002.
Statistics Norway. 2020. Jordbruksbedrifter med husdyr og jordbruksbedrifter med ymse husdyrslag per 1. mars. Accessed May 13 2020. https://www.ssb.no/jord-skog-jakt-og-fiskeri/statistikker/ jordhus.

Stevenson, M., T. Neuner, C. Heuer, J. Marshall, J. Sanchez, R. Thornton, J. Reiczigel, J. Robison-Cox, P. Sebastiani, P. Solymos, K. Yoshida, G. Jones, S. Pirikahu, S. Firestone, R. Kyle, and J. Popp. 2017. epiR: Tools for the Analysis of Epidemiological Data. $\mathrm{R}$ package version 0.9-91. https://CRAN.R-project.org/package $=$ epiR.

Sullivan, L. E., N. J. Evans, R. W. Blowey, D. H. Grove-White, S. R. Clegg, J. S. Duncan, and S. D. Carter. 2015. A molecular epidemiology of treponemes in beef cattle digital dermatitis lesions and comparative analyses with sheep contagious ovine digital dermatitis and dairy cattle digital dermatitis lesions. Vet. Microbiol. 178:77-87. https://doi.org/10.1016/j.vetmic.2015.04.011.

Thomsen, P. T., I. C. Klaas, and K. Bach. 2008. Short communication: Scoring of digital dermatitis during milking as an alternative to scoring in a hoof trimming chute. J. Dairy Sci. 91:4679-4682. https://doi.org/10.3168/jds.2008-1342.

Toft, N., G. T. Innocent, G. Gettinby, and S. W. Reid. 2007. Assessing the convergence of Markov Chain Monte Carlo methods: An example from evaluation of diagnostic tests in absence of a gold standard. Prev. Vet. Med. 79:244-256. https://doi.org/10.1016/. .prevetmed.2007.01.003.

Trott, D. J., M. R. Moeller, R. L. Zuerner, J. P. Goff, W. R. Waters, D. P. Alt, R. L. Walker, and M. J. Wannemuehler. 2003. Characterization of Treponema phagedenis-like spirochetes isolated from papillomatous digital dermatitis lesions in dairy cattle. J. Clin. Microbiol. 41:2522-2529. https://doi.org/10.1128/JCM.41.6.2522 $-2529.2003$.

Vink, W. D., G. Jones, W. O. Johnson, J. Brown, I. Demirkan, S. D. Carter, and N. P. French. 2009. Diagnostic assessment without cut-offs: Application of serology for the modelling of bovine digital dermatitis infection. Prev. Vet. Med. 92:235-248. https://doi.org/ 10.1016/j.prevetmed.2009.08.018.

Wells, S. J., L. P. Garber, and B. A. Wagner. 1999. Papillomatous digital dermatitis and associated risk factors in US dairy herds. Prev. Vet. Med. 38:11-24. https://doi.org/10.1016/S0167-5877(98)00132 -9 .

\section{ORCIDS}

Ingrid H. Holmøy ํㅜ https://orcid.org/0000-0003-3742-8011 Jenny Frössling @ https://orcid.org/0000-0001-5949-6985

Ane Nødtvedt ( https://orcid.org/0000-0002-4137-5103

Terje Fjeldaas (®) https://orcid.org/0000-0003-3781-1934 